\title{
Malaria Prevention: Knowledge, Attitude And Practice In A Southwestern Nigerian Community.
}

\author{
ERHUN W. $.0^{1^{*}}$, AGBANI E. $0^{2}$ AND ADESANYA S. $0^{1}$ \\ Department of Clinical Pharmacy and Pharmacy Administration, Obafemi Awolowo \\ University, Ile-Ife, Nigeria.
}

Received: July, 2004

Accepted: December, 2004

\begin{abstract}
Assessing and analyzing local malaria problems are a prerequisite for successful control interventions. We sought to assess the knowledge of the symptoms of malaria, attitude towards preventive measures as well as treatment seeking behaviors among members of the lle-lfe community in southwestern Nigeria. A cross sectional study was carried out using a questionnaire, which was self or researcher administered to community members of semiurban lle-lfe. Analysis of "what respondents will do first" during malaria attack showed that $35.5 \%, 0.9 \%$ and $13.4 \%$ of respondents will use synthetic anti-malarials, consult a herbalist and use local herb, respectively, while $27.3 \%, 1.7 \%$ and $18.2 \%$ will go to the hospital, take spiritual/ritual waters for cure and just pray, respectively, with $3.0 \%$ of the respondents indicating that they will ignore the signs. Factors influencing respondents' choice of malaria treatment and preventive methods included cost, religious beliefs, perceived safety, convenience and respondents' state of health for $22.7 \%, 5.4 \%, 20.8 \%$, $26.5 \%$ and $24.6 \%$ of the respondents, respectively. The use of insecticide impregnated net are uncommon amongst the respondents $(0 \%)$. Treatment seeking practice in malaria was related to level of education and religion. We found that convenience and the severity of the disease affected respondents' choice of treatment in more than $50 \%$ of the cases. We suggest that malaria public enlightenment efforts should be intensified, effective malaria preventive methods be made affordable and that support be provided to make malaria treatments at public hospitals free.
\end{abstract}

Key words:

Malaria, Attitudes, insecticide treated nets,

\section{INTRODUCTION}

Annually, malaria kills more people in the tropics than any other infectious disease. The human and economic costs associated with declining quality of life, consultations, treatments, hospitalizations and other events related to malaria are enormous and often lead to low productivity and lost incomes. Experiences with malaria have shown that prevention is better and cheaper than cure; however the practice of malaria preventive measures has been related to the knowledge and belief of people and have been found to be low and difficult to implement when malaria risk is perceived to be low (Winch et al, 1994). Malaria-related knowledge, attitudes and practices (MKAP) have been examined in many rural and partly urban multiethnic populations in Africa (Okrah et al, 2002; Tsuyuoka et al, 2001; Dossou-Yov et al, 2001). Within Nigeria, surveys of residents of the Atlantic coast revealed a lack of knowledge and many misconceptions about the transmission and treatment of malaria, which could adversely affect malaria control measures and anti-malarial therapy (Afolabi- Web resource). Recommendations that preventive measures be incorporated into malaria alleviation programs in addition to developing an appropriate educational intervention strategy highlighting the importance of compliance have been made following results of "perceived malaria" management in a Nigerian setting Erhun et al, 2002). MKAP is thus becoming more important to the design and improvement of malaria control activities, to the establishment of 
epidemiological and behavioral baselines and to identifying indicators for monitoring intervention programs (Schultz et al, 1994).

This paper reports the results of the survey carried out to assess the MKAP of the multiethnic population of Ile-Ife town, Nigeria. Specific objectives were to ascertain the levels of knowledge regarding malaria, investigate attitudes and practices in the prevention and treatment of malaria and examine attitudes towards bednets and insecticide treatment

\section{MATERIALS AND METHODS}

A pre-coded questionnaire was self or researcher administered in a face-to-face interview approach. A team of 8 interviewers was trained by the researchers for three days before the start of data collection. The questionnaire was translated into Yoruba and a pre-test was conducted in Aba gboro and Parakin areas of lle-Ife. Three hundred and twenty questionnaires were produced including 20 which were pre-tested across age and sex variables of target respondents. The results of the pretest were excluded from the analysis. The purpose of the study was very carefully explained to the target population (mainly decision makers for each selected household) and their consent individually obtained before the questionaire was administered. Ile-lfe (the study site) is an urban town in southwestern Nigeria; it lies in the tropical rain forest belt and has an estimated population of about 282,000. lle-lfe has many satellite villages that are linked by a poor road network. For the most part, the villages have poorly developed infrastructures, often without access to either electricity or pipeborne water. For this study, lle-lfe (Figure 2) was divided into four regions consisting of 13 districts namely Iloromu, Ita-Olorun, Ibadan road, Eleiyele, Lagere, Modakeke, Igboya, Idio, llode, Arubidi, Iloro, Fashina and llesha road; one district was selected from each region into the sample to ensure geographic representation. The districts surveyed included Fashina in the central region, lbadan road in the western region, llesha road in the eastern region, and Modakeke in the southern region.

Sample selection involved the use of a twostage cluster random sampling procedure at the district level to select sub districts and zones from where the study sample could be drawn. In each district, the area was broken down to sub districts from which three zones were selected based on population. Within the selected zones, households were randomly numbered, and houses assigned 'odd number' were selected into the final sample. A key decision-maker respondent (male or female) was identified for interview in the final sample population. Knowledge of malaria signs and symptoms, prevention methods such as bush clearing, use of insecticide impregnated nets, removal of stagnant water, use of insecticide, fumigation of homes and environment and the use of prophylactic anti-malarials were the main outcomes measured as determinants for "malaria prevention." Statistical analysis was done using the SPSS version 10.0 software program. The research was funded by the authors.

\section{RESULTS}

\section{Sample structure}

A total of 300 face-to-face interviews were conducted with respondents at their households. The sample was allocated to each district in proportion to its population. Proportionality was used in the allocation of sample down to the zone level. A large proportion of the sample was drawn from the districts of Ibadan road and Modakeke as they had the largest population among selected districts. The sample comprised about $63 \%$ male and $37 \%$ female respondents. This was designed to ensure a proportionate gender representation because both men and women play an important role in household decision making. Only 231 of the target population of 300 decision makers, (one for each sampled household) responded with 69 withdrawing (for reasons ranging from perceived anxieties that the results may be used for purposes other than earlier explained by the researchers and to what appears to be a general lack of enthusiasm toward surveys and apathy towards interventions perceived to be government oriented. There were questionnaires 'dropped' at the request of some household decision makers after initial interview that could not be retrieved as at collation time after several return visits, these were also tagged "withdrawn"

\section{Age distribution, education level and socio- economic status of respondents}

The majority of respondents were in the 18-40 age group (approx $70 \%$ of respondent) and approximately $30 \%$ were above 40 years old (Table 1) More than $23 \%$ of the respondents earned less than the national minimum wage $(7,500$ naira) (Table 1$)$ while over $15 \%$ were without formal education (Table 2). Most households that were surveyed had 4 to 7 people $(41.5 \%)$ and an average household size of six people. About $11 \%$ of households had nine or more members.

\section{Risk perception, malaria treatment and prevention factors}

The results indicated that over $90 \%$ of the respondents have had malaria at least once in the last one year and practice self medication. Most $(73.5 \%)$ of the respondents willing to go to the hospital in the event of malaria attack, to use untreated bed nets $(81.2 \%)$, insecticides sprays $(72.4 \%)$ and insecticide treated nets $(88.7 \%)$ as 
Table 1

Respondents' Sex, Age and Income Group Distribution

\begin{tabular}{|c|c|c|c|c|c|}
\hline Sex & & & Male & Female & Total \\
\hline Frequency & & & 146 & 85 & 231 \\
\hline \% distribution in studied population & & & $63.20 \%$ & $36.80 \%$ & 100 \\
\hline Age group & $18-30$ & $31-40$ & $41-50$ & $>50$ & Total \\
\hline Age Frequency & 101 & 56 & 49 & 25 & 231 \\
\hline$\%$ distribution in studied population $\approx$ & $43.72 \%$ & $24.24 \%$ & $21.21 \%$ & $10.82 \%$ & $100 \%$ \\
\hline Income group/month & & \multicolumn{4}{|c|}{ Frequency and \% within studied population } \\
\hline Less than $\$ 05,000$ & & 54 & $\rightarrow \quad 23.4 \%$ & & \\
\hline$\$ 05,000-\$ 10,000$ & & 26 & $11.3 \%$ & & \\
\hline$\$ 11,000-\$ 20,000$ & & 40 & $\rightarrow \quad 17.3 \%$ & & \\
\hline$\$ 21,000-\$ 30,000$ & & 19 & $8.2 \%$ & & \\
\hline$\$ 31,000-\$ 40,000$ & & 17 & $\rightarrow \approx 7.3 \%$ & & \\
\hline$\$ 41,000-\$ 50,000$ & & 11 & $4.8 \%$ & & \\
\hline More than $₫ 50,000$ & & 25 & $10.8 \%$ & & \\
\hline No income & & 39 & $16.8 \%$ & & \\
\hline
\end{tabular}

Table 2

Distribution of Respondents' Education Level and Occupation

\begin{tabular}{|c|c|c|}
\hline Education level & \multicolumn{2}{|c|}{$\begin{array}{c}\text { Frequency and \% within studied } \\
\text { population }\end{array}$} \\
\hline Never attended school & 35 & $\rightarrow \approx 15.15 \%$ \\
\hline Some or completed Primary education & 27 & $\rightarrow \approx 11.69 \%$ \\
\hline Some or completed secondary education & 83 & $\rightarrow \approx 35.93 \%$ \\
\hline Above secondary education & 86 & $\rightarrow \approx 37.23 \%$ \\
\hline Total & 231 & $\rightarrow \approx 100 \%$ \\
\hline Occupation & \multicolumn{2}{|c|}{$\begin{array}{c}\text { Frequency and \% within studied } \\
\text { population }\end{array}$} \\
\hline Farmer/trader & 39 & $\rightarrow \quad \approx 16.87$ \\
\hline Private/public professional & 36 & $\rightarrow \quad \approx 15.58$ \\
\hline Non professionals in private and civil establishment & 112 & $\rightarrow \quad \approx 48.48$ \\
\hline Clergy men/women & 12 & $\rightarrow \approx 05.19$ \\
\hline Students/lay/unskilled workers & 32 & $\rightarrow \approx 13.80$ \\
\hline Total & 231 & $\rightarrow \approx 100 \%$ \\
\hline
\end{tabular}

preventive measures have above secondary education.

Most of the respondents (> 60\%) are familiar with at least 3 signs/symptoms associated with malaria as defined by western medicine; $68.3 \%$, $67.4 \%, 61.8 \%, 19.6 \%, 10.0 \%$ and $4.3 \%$ of respondents reported fever, headache, body pains, dizziness, vomiting and diarrhea respectively, as common symptoms of malaria.

Table 3 shows malaria prevention methods studied and the respondents' knowledge and practice of these measures. Figure 1 is an attempt to simulate the willingness of the respondents to use selected malaria preventive methods. Analysis of "what respondents will do first" during malaria attack showed that $35.5 \%$, $0.9 \%$ and $13.4 \%$ of respondents will use synthetic anti-malarias, consult a herbalist or use local herbs, respectively, while $27.3 \%, 1.7 \%$ and $18.2 \%$ will go to the hospital, take spiritual/ritual waters for cure or just pray, respectively, with $3.0 \%$ of the respondents indicating that they will ignore the signs. Factors influencing respondents' choice of malaria treatment and preventive methods include cost (22.7\%), religious beliefs (5.4\%), perceived safety (20.8\%), convenience (26.5\%) and respondents' state of health $(24.6 \%)$. 
Table 3

Respondent knowledge and practice of malaria preventive measures

\begin{tabular}{|c|c|c|c|c|c|c|c|c|c|}
\hline & & & Sel & cted m & thods 0 & malaria & orevent & & \\
\hline & $\begin{array}{l}\text { Mthd. } \\
\text { ? }\end{array}$ & $\begin{array}{l}\text { Mthd } \\
\text { II? }\end{array}$ & $\begin{array}{l}\text { Mthd. } \\
\text { III? }\end{array}$ & $\begin{array}{l}\text { Mthd. } \\
\text { N? }\end{array}$ & $\begin{array}{l}\text { Mthd. } \\
\text { V? }\end{array}$ & $\begin{array}{l}\text { Mthd. } \\
\text { VI? }\end{array}$ & $\begin{array}{l}\text { Mthd. } \\
\text { VII? }\end{array}$ & $\begin{array}{l}\text { Mthd. } \\
\text { VIII? }\end{array}$ & $\begin{array}{l}\text { Mthd. } \\
\text { IX? }\end{array}$ \\
\hline $\begin{array}{l}\text { Percentage of respondents } \\
\text { perceiving method as available }\end{array}$ & 86.5 & 41.7 & 64.3 & 77 & 31.7 & 75.7 & 31.3 & 62.6 & 40.3 \\
\hline $\begin{array}{l}\text { Percentage of respondents } \\
\text { preferring method of prevention }\end{array}$ & 21.7 & 6.2 & 6.8 & 18.1 & 4.0 & 20.2 & 3.3 & 14.4 & 5.3 \\
\hline $\begin{array}{l}\text { Percentage of respondents } \\
\text { currently using method of } \\
\text { prevention. }\end{array}$ & 35.9 & - & - & - & - & 40.4 & - & 23.7 & - \\
\hline $\begin{array}{l}\text { Indicates: } \\
\text { Mthd. I - Bush clearing; Mthd. II } \\
\text { Mthd. IV - Removing stagnant } \\
\text { Mthd. VI - Use of insecticide spr } \\
\text { Mthd. VIII - Use of antimalaria a }\end{array}$ & thd. VII & $\begin{array}{l}\text { ironm } \\
\text { - Use } \\
-U s\end{array}$ & Us & $\begin{array}{l}\text { f untre } \\
\text { - }-C \\
\text { de imp } \\
\text { ia prop }\end{array}$ & $\begin{array}{l}\text { ed bec } \\
\text { ering o } \\
\text { gnated } \\
\text { lactics }\end{array}$ & $\begin{array}{l}\text { net; } \\
\text { g wells, } \\
\text { ets }\end{array}$ & & & \\
\hline
\end{tabular}

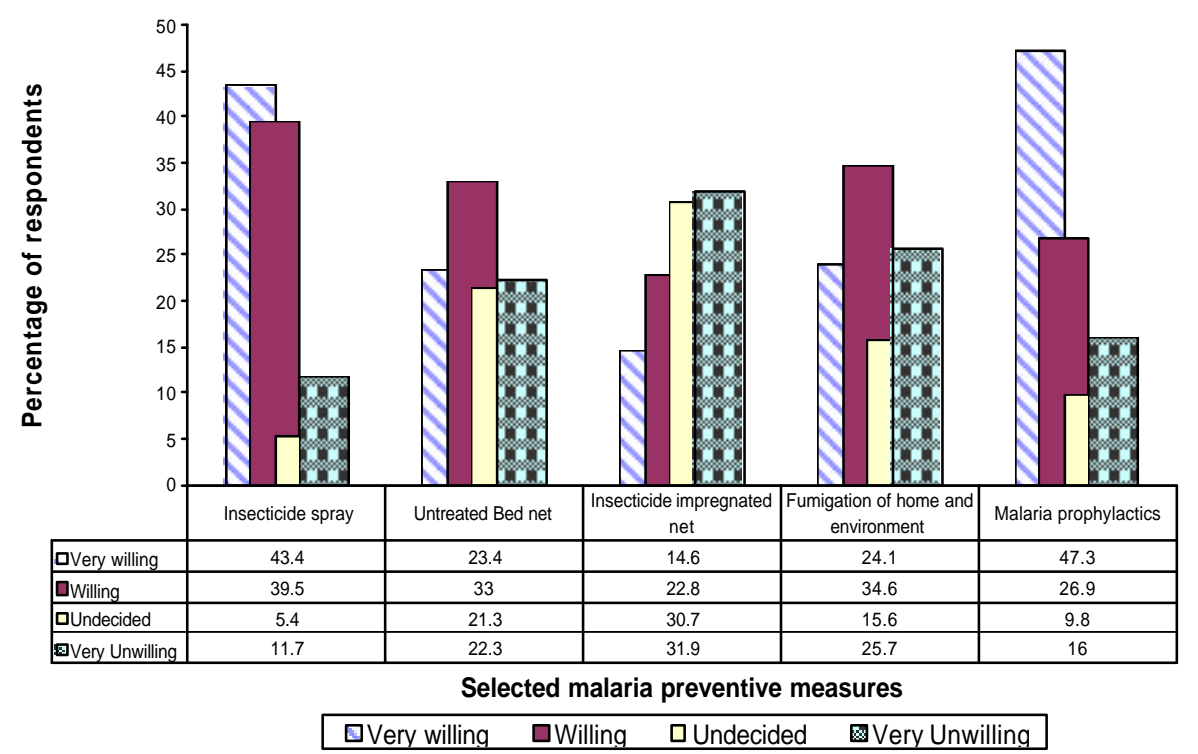

Fig. 1

Simulation of respondents willingness to use selected malaria preventive measures

\section{DISCUSSION}

Malaria intervention goals in endemic areas should be to prevent mortality and reduce morbidity as well as associated socio-economic losses. This requires the progressive creation of capacities for assessing local malaria situation and the selection of appropriate control measures. The study highlights respondents' perception of vector control methods and shows that the use of untreated bed nets, fumigation and insecticide impregnated bed nets were not common in the communities studied (Figure 1); for reasons bordering mostly on perceived ineffectiveness and inconvenience. The use of bed nets reduce the degree of human-vector contact and malaria transmission and the prevalence of malaria infection can be significantly lowered by the use of insecticide impregnated bed nets (Erhun.et al, 2002; El Nur, 1995-2000; Schultz et al, 1994). Thus, report shows that impact on malaria of insecticidetreated nets seems good when compared with spraying trials (Mathenge et al, 2001). The survey reveals that many of the respondents do not know that nets could be impregnated with insecticides $(68.7 \%$, Table 3$)$ not to mention using it as a control measure. A sizeable proportion $(86.5 \%)$ of the study population sees bush clearing as effective malaria prevention method and about 36\% are currently using this method (Table 3 ). Generally this may not be an effective method for malaria prevention. While current international effort at malaria control are targeted toward the use of insecticide treated nets (ITN) for prevention via vector control $(8,9$, 10 ) only $31.3 \%$ of the respondents perceive this as an available malaria prevention method and $3.3 \%$ preferring it as method of malaria prevention with no respondent currently using ITN (Table 3). It is paradoxical that the respondents were willing to buy malaria prophylactics and insecticide sprays yet unwilling to utilize insecticide treated bed nets. Perhaps the initial purchase cost may be a major factor here especially as over $50 \%$ of the respondents earn $\mathrm{N} 20,000$ or less and are the 
major or sole providers in households of 4-7 people.

Special strategies are needed to deliver subsidized ITNs to vulnerable populations in areas where malaria and poverty are most severe. The lack of shops with ITNs can be a major constraint to bednet ownership and use in these areas. Educating community members regarding the beneficial effects of using insecticide impregnated bed nets and implementing their use is an appropriate intervention to achieve high control of malaria vectors in endemic areas (Mathenge et al, 2001)) like lle-lfe of Nigeria.

The results indicate that the study population has a fair knowledge of the life cycle of malaria vectors as over $75 \%$ agreed that stagnant water could serve as breeding sites for mosquitoes (Table 3). Similarly, most of the respondents (> $60 \%$ ) were familiar with the signs and symptoms associated with malaria; this is expected for a population in a malaria endemic area and with close to $80 \%$ having been formally educated. However a large percentage of the respondents practice self-medication; this is a very common practice in most malaria endemic countries (www.rbm.who.int; Curtis et al, 2000) Convenience and the severity of the disease were major indicators in over $50 \%$ of the respondents' choice' of treatment, thus indicating that they were used to malaria and have a reduced malaria risk perception. The endemic nature of the disease and the respondents confidence in self medication appear to make malaria "trivial" - a perception that is at variance with the emergence of drug resistant strains of malaria parasites from inappropriate therapy. Additionally, the study established a relationship between levels of education and appropriate malaria risk perception and attitude; as over $72 \%$ of respondents willing to go to the hospital in the event of malaria attack, use untreated bed nets, insecticide sprays and insecticide treated nets as preventive measures are educated to at least secondary school level. The socio-economic challenges in Nigeria have led many into looking unto a divine being for succor; however, The study showed that a sizeable percentage $(19.9 \%)$ of the respondent population will first resort to spiritual means as a treatment method during a malaria incident.

This is not very surprising since the belief in divine healing is not uncommon in the part of the country covered by this study. This may indicate a lack of confidence in malaria medicines.

\section{Conclusion}

Malaria public enlightenment efforts need be intensified, effective malaria preventive methods should be affordable and support should be provided to make malaria treatments at hospitals free.

\section{REFERENCES}

Afolabi. B.M. Knowledge, attitude and practice of malaria in an isolated community on the Atlantic coast of Lagos, Nigeria. Web resource.- Malaria and infectious diseases in Africa/ Paludisme et maladies infectieuses en Afrique. www.chez.com/malaria/04ansu02.htm

Curtis, C.F., and Mnzava, A.E.P. (2000), Comparison of house spraying and insecticide treated nets for malaria control. Bulletin of the World Health Organization. 78 (12) \# World Health Organization 2000. Ref. No. 00-0809

Dossou-Yovo J, Amalaman K, Carnevale P (2001). Antimalarial guidelines and therapy practices of the population of Bouake, Ivory Coast Med. Trop. (Mars) 61(6): 495-9

EI Nur O.A. (1995-2000). Bed nets impregnated with insecticides for control of malaria vectors in Sudan TDR/EMRO final report summary

Erhun., W.O. and Adebayo., A (2002). Students' management of perceived malaria in a Nigerian University. Journal of Social and Administrative Pharmacy. 19(4) .

Mathenge, E.M., Gimnig, J.E., Kolczak, M., Ombok, M., Irungu, L.W., and Hawley, W.A., (2001). Effect of permethrin-impregnated nets on exiting behavior, blood feeding success, and time of feeding of malaria mosquitoes (Diptera: Culicidae) in Western Kenya $J$. Med. Entomol.; 38(4): 531- 536

Okrah J, Traore C, Pale A, Sommerfeld J, Muller O (2002). Community factors associated with malaria prevention by mosquito nets: an exploratory study in rural Burkina Faso. Trop. Med. Int. Health. 7(3): 240-8 Schultz, L.J., Effling, M., Chitsulo, L., Steketee, R.W., Nyasulu, Y., Macheso, A., Nwanyanwu, O.C (1994). A nationwide malaria knowledge, attitude and practices survey in Malawi: objectives and methodology. Trop. Med. and Parasit, 45: 5456.

Tsuyuoka, R, Wagatsuma, Y, Makunike B (2001). The knowledge and practice on malaria among community members in Zimbabwe. Cent. Afr. J. Med.; 47(1): 14-7

Web resource http://www.rbm.who.int/ newdesign2/bednets/bednets.htm

Winch, P.J., Makemba, A.M., Kamazina, S.R., Lwihula, G.K., Lubega, P., Minjas, J.N., Shiff, C.J (1994). Seasonal variation in the perceived risk of malarial, Implication for promotion of insecticide impregnated bednets. Social Science and Medicine,; 39: $63-75$

\section{Corresponding author.}

Dr. W.O Erhun, Department of Clinical Pharmacy and Pharmacy Administration, Faculty of Pharmacy, Obafemi Awolowo University, Ile-Ife, Nigeria. E-mail-werhun@oauife.edu.ng, Phone 0803-7233-500 